\title{
Angelica Seed Oil
}

National Cancer Institute

\section{Source}

National Cancer Institute. Angelica Seed Oil. NCI Thesaurus. Code C107263.

The oil extracted from the seeds of Angelica archang elica. Angelica seed oil is used primarily in aromatherapy. 